\title{
Preliminary Results in Anatomic All-inside Anterior Cruciate Ligament Reconstruction
}

\author{
Octav Russu1', Tiberiu Bățagă¹, Andrei-Marian Feier', Radu Prejbeanu², Radu Fleaca³, Mihai \\ Roman ${ }^{3}$, István Gergely ${ }^{1}$ \\ ${ }^{1}$ University of Medicine and Pharmacy, Tîrgu Mureș, Romania \\ 2 "Victor Babeș" University of Medicine and Pharmacy, Timișoara, Romania \\ 3 “Victor Papillan” Faculty of Medicine, "Lucian Blaga” University, Sibiu, Romania
}

\section{CORRESPONDENCE}

\section{Andrei Marian-Feier}

Str. Gheorghe Marinescu nr. 38

540139 Tîrgu Mureș, Romania

Tel: +40 747501392

E-mail: andreifeier@gmx.com
Octav Russu • Str. Gheorghe Marinescu nr. 38 , 540139 Tîrgu Mureș, Romania. Tel: +40 265215 551, E-mail: octav@genunchi.ro

Tiberiu Bățagă • Str. Gheorghe Marinescu nr. 38 , 540139 Tîrgu Mureș, Romania. Tel: +40 265215551 E-mail: tbataga@gmail.com

Radu Prejbeanu • P-ța Eftimie Murgu nr. 2, 30004 Timișoara, Romania. Tel: +40 256204 400, E-mail: raduprejbeanu@gmail.com

Radu Fleaca • Str. Lucian Blaga nr. 2A, 550169 Sibiu, Romania. Tel: +40 269212 320, E-mail: rfleaca@ yahoo.com

Mihai Roman • Str. Lucian Blaga nr. 2A, 550169 Sibiu, Romania. Tel: +40 269212 320, E-mail: mihaidanroman@yahoo.com

István Gergely • Str. Gheorghe Marinescu nr. 38 540139 Tîrgu Mureș, Romania. Tel: +40 265215551

E-mail: gergelyistvan@studium.ro

\begin{abstract}
Introduction: Anterior cruciate ligament $(A C L)$ rupture is one of the most common lesions in knee traumatology; therefore the number of $A C L$ reconstructions is increasing worldwide. Usually, an anteromedial (AM) accessory portal is required in anatomical positioning of the femoral tunnel, which is not absolutely necessary in this technique. Aim: Assessment of all-inside ACL reconstruction preliminary clinical results with adjustable loops and buttons on both femoral and tibial surfaces. Method: Our prospective study included 28 subjects (19 male, 9 female) with chronic ACL ruptures. The mean age of the study population was $27.72 \pm 8.23$ years. In all cases ACL reconstruction was carried out with the use of quadrupled semitendinosus autografts with adjustable loops and buttons on the femoral and tibial surfaces and anatomic placement of both tunnels, using an outside-in technique, with flipcutters (Arthrex ${ }^{\circledR}$ ). Clinical and radiological evaluations were carried out before surgery and at 3 and 6 months postoperatively, with the Lysholm scoring system, the Tegner activity scale and anterior-posterior and laterolateral X-rays. Anterior knee laxity was measured in $25^{\circ}$ of flexion using a portable arthrometer (RolimeterTM, Aircast ${ }^{\circledR}$ ) and maximum manual force. Results: During the final follow-up, the Lysholm score was good and excellent in 27 cases, with a mean Lysholm score of $95.55 \pm 4.63$; all results were classified as good. The mean preoperative Tegner activity score was $3.46 \pm 1.71$ (range: 1-7), and the post-operative mean score was $5.75 \pm 2.24$ (range: $2-10$ ). We found no graft ruptures. Preoperative knee laxity measurements showed a mean displacement of 11.5 $\pm 3.1 \mathrm{~mm}$ and side-to-side differences of $5.6 \pm 3.5 \mathrm{~mm}$, while the postoperative measurements at the last follow-up were $6.3 \pm 1.54 \mathrm{~mm}$ and $2.65 \pm 1.86 \mathrm{~mm}$, respectively. Conclusion: Shortterm clinical outcomes of all-inside ACL restoration with anatomic placement femoral and tibial tunnels seem to recommend this surgical option, with good subjective and objective results. Additional research will have to prove the long-term success.
\end{abstract}

Keywords: anterior cruciate reconstruction, hamstring, all-inside, anatomic placement

\section{INTRODUCTION}

Anterior cruciate ligament restoration with a complete tibial bone tunnel is a common orthopedic surgery technique, and its use evolved remarkably in recent years. ${ }^{1}$ Usually, an anteromedial (AM) accessory portal is required for the anatomical positioning of the femoral tunnel. In the all-inside procedure, the 
classic tibial and femoral osseous tunnels are replaced with a socket, and are drilled using an outside-in method, without the necessity of an accessory AM portal. The procedure was associated with reduced surgical invasion, faster recovery after the surgery, and reduced pain. ${ }^{2-6} \mathrm{Be}-$ ing a new technique, only few studies have reported the clinical and functional outcomes following all-inside ACL restoration. ${ }^{7,8}$ Therefore, our main objective was to assess the functional and clinical effectiveness of the anatomic all-inside ACL restoration technique during the 6 months follow-up.

\section{METHODS}

A prospective, single-center study was carried out in the Orthopedics and Traumatology Clinic No. 2 of Tîrgu Mureș, Romania. After obtaining patient informed consent, we included 28 patients aged 14 to 36 years with an ACL-deficient knee, who opted to have ACL reconstructive surgery with autograft semitendinosus tendons. The inclusion criteria were active patients who could not recommence their pre-injury level of activity due to instability concerns, and complete rupture of the ACL (as described by a radiologist on the magnetic resonance images). ${ }^{1,2}$ Exclusion criteria were revision procedures, ${ }^{1}$ previous high tibial osteotomy or other knee ligament reconstructions, ${ }^{2,3}$ previous contralateral ACL reconstructions and chondral or subchondral lesions higher than grade 2 (Outerbridge classification). ${ }^{4,5}$ In all cases, the ACL reconstruction was carried out with quadrupled semitendinosus autografts, with adjustable loops and buttons on the femoral and tibial side and anatomic placement of both tunnels, using an outside-in technique, with flipcutters $\left(\right.$ Arthrex $\left.^{\circ}\right)$. All the interventions were performed by a senior orthopedic-trauma surgeon or under his guidance. The patients had been followed-up at 3 and 6 months postoperatively.

\section{Assessment of the results}

Functional outcome measures, including the Lysholm score and Tegner activity scale were used to assess the results, and were calculated before surgery, at each scheduled follow-up visit (3 and 6 months postoperatively). During the last visit, the anterior knee laxity was measured in $25^{\circ}$ of flexion using a compact arthrometer (RolimeterTM, Aircast ${ }^{\circ}$ ) and maximum manual force. Anteroposterior and latero-lateral radiographs were performed preoperatively and at 6 months postoperatively in order to visualize the position of the buttons on the femoral and tibial surfaces.
The Lysholm Knee Scoring Scale is commonly applied to assess the results of knee ligament operations. Its first description was published in 1982, and even after 25 years of its implementation, the Lysholm score demonstrated acceptable psychometric parameters as a patient-administered score. 9 The current version contains 8 subscales (limp, support, locking, instability, pain, swelling, stair climbing and squatting). The values from each subscale are summed in order to provide a total normalized score. Scores vary from 0 to 100 , a higher value meaning a better outcome (excellent 95-100; good 84-94; fair 65-83; poor <64).

The Tegner Activity Scale seeks to offer a standardized system of grading functional daily and sports activities. It is often used in combination with the Lysholm Knee Scoring Scale to assess subjects with ACL injuries. A score of 0 equals retirement or disability due to knee difficulties, while a score of 10 corresponds to participation in elite competitive sports.

\section{Statistical analysis}

Descriptive statistics (mean, median, standard deviation) are reported for the included study population. Statistical analysis compared the results for each follow-up period (before the surgery and at 3 and 6 months postoperatively). Demographic variables (sex, age, level of education) and smoking status were also examined. Differences between the scores were tested with the chi-square, t-test and 2-way repeated ANOVA measurements. A value of $p$ equal to 0.05 is considered statistically significant. All calculations were carried out using Microsoft Excel (Microsoft, Redmond, WA), and GraphPad (InStat) and EpiInfo v. 7.1.4.0 (Centers for Disease Control and Prevention, Atlanta, USA).

\section{RESULTS}

Follow-up at 6 months was achieved for every patient included in our study. There were 19 male (68\%) and 9 female (32\%) patients, with a mean age at surgery of 27 years (14 to 36 years). Other demographic characteristics, associated lesions and smoking status are presented in Table 1. The mechanism of injury occurred during sports in 13 (46\%) patients. A noncontact valgus-twisting deceleration situation was reported in 7 out of 13 cases, and a minorenergy trauma for the others. Twenty patients presented with additional associated lesions, out of which 17 had meniscal injuries. The main symptoms reported were instability in all cases, with swelling in 3 cases, and with pain alone in 5 patients. Injury to surgery mean time was 14 
TABLE 1. Patient demographics and characteristics

\begin{tabular}{lc}
\hline Variable & Value \\
\hline Sex, male/female, $\mathrm{n}$ & $19 / 9$ \\
Age at surgery, y, mean $\pm \mathrm{SD}$ & $27 \pm 8.2$ \\
Body mass index, mean $\pm \mathrm{SD}$ & $24 \pm 3.1$ \\
Injury to surgery time, mo, mean \pm SD & $14 \pm 23$ \\
Meniscus lesions, $\mathrm{n}$ & 11 \\
$\quad$ Medial & 6 \\
Lateral & 3 \\
Collateral ligaments injury, $\mathrm{n}$ & - \\
Medial & 11 \\
Lateral & \\
Smokers, $\mathrm{n}$ & 15 \\
Level of education & 13 \\
Less than high school & \\
High school diploma or above & \\
\hline
\end{tabular}

months (range 3 to 37 months). One patient developed a graft infection that required conservative treatment with intravenous antibiotic therapy (oxacillin and gentamicin) and immobilization for three weeks.

The mean graft diameter for the ACL autografts was $8 \pm$ $1.11 \mathrm{~mm}$ (range 6.2 to $9.6 \mathrm{~mm}$ ). Patient outcomes for preoperative, as well as 3 and 6 months postoperatively are presented in Table 2. The mean \pm SD Lysholm score was $53.8 \pm 5.5$ before the reconstruction and $95.55 \pm 4.6$ at the final 6-month follow-up ( $\mathrm{p}<0.0001$ ). The Tegner Activity Scoring scale differed significantly $(\mathrm{p}<0.0001)$ from baseline $(3.46 \pm 1.7)$ compared to the last postoperative evaluation $(5.75 \pm 2.2)$. The mean anterior laxity measured with the Rolimeter device was $11.4 \pm 0.8 \mathrm{~mm}$ before surgery and decreased significantly to $6.3 \pm 1.5 \mathrm{~mm}$ at the 6 months follow-up ( $\mathrm{p}<0.0001)$.

Radiographic assessment during the last follow-up proved an accurate TightRope button position in all patients, with no pathologic changes. There were no graft ruptures during the study, and no patient demonstrated limited range of motion at the final assessment. No differences in regards to Lysholm score, Tegner activity level and anterior-posterior knee laxity were found between smokers and non-smokers. The level of education had no significant influence on the outcomes.

\section{DISCUSSIONS}

The primary finding of our study was that anatomic allinside ACL reconstruction showed good to excellent functional outcomes. Anteroposterior knee instability was restored at 6 months postoperatively, without complications such as stiffness, limited range of motion or persistent instability. Lysholm scores and Tegner activity scores were significantly improved at 6 months follow-up compared with baseline. Even if the all-inside technique used for the ACL reconstruction has been used for several years, its clinical and functional effectiveness has not been intensively studied. In 2015, Schurz et al. published a study evaluating clinical and functional results after ACL restoration by using the all-inside method. ${ }^{7}$ Similarly to our findings, they found a considerable improvement in Lysholm scores when comparing preoperative and postoperative scores (53.4 vs 93.1, $\mathrm{p}<0.0001$ ), but with a longer clinical followup (24 months). Tegner Activity Scoring Scale level also differed from preoperative state to the last follow-up (2 vs. $6, \mathrm{p}<0.0001)$. In addition to our study, they also evaluated the outcomes with the International Knee Documentation Committee (IKDC) score and analyzed pain level comparing the Visual Analogue Scale (VAS) before and after the intervention. Significant VAS changes were observed at 24 months of follow-up ( 5 vs. $0.1, \mathrm{p}<0.0001$ ) compared to baseline. The IKDC score also differed significantly, with a score of 44.6 before the surgery and 89.7 at 2 years after the intervention $(\mathrm{p}<0.0001)$. In a prospective study, Lubowitz et al. compared the outcomes between the allinside technique and full tibial tunnel technique with a 24-month follow-up. ${ }^{8}$ At final follow-up, IKDC was no different between the groups, but VAS had significantly improved in the all-inside technique group, proving the clinical effectiveness of the procedure. Hussein et al. compared the single-bundle (SB) and double-bundle (DB) anatomic ACL restoration methods, evaluating the outcomes using Lysholm score, IKDC score, knee instability and pivot-

TABLE 2. Patient outcomes

\begin{tabular}{lcccc}
\hline & Preoperative & $\begin{array}{c}\text { Postoperative } \\
\text { at 3 months }\end{array}$ & $\begin{array}{c}\text { Postoperative } \\
\text { at } \mathbf{6} \text { months }\end{array}$ & $\begin{array}{c}\text { Preoperative } \\
\text { vs. 6 months } \\
\text { (p value) }\end{array}$ \\
\hline Lysholm score & $53.8 \pm 5.5$ & $75.2 \pm 10$ & $95.5 \pm 4.6$ & $<0.0001$ \\
Tegner score & $3.4 \pm 1.7$ & $5.5 \pm 0.9$ & $5.7 \pm 2.2$ & $<0.0001$ \\
Laxity, mm (Rolimeter) & $11.4 \pm 0.8$ & $6.3 \pm 1.5$ & $6.3 \pm 1.5$ & $<0.0001$ \\
\hline
\end{tabular}


shift test for rotational instability, with a follow-up of 30 months. ${ }^{10}$ They did not find any significant differences between the anatomic SB and DB techniques with respect to the Lysholm score (93.9 vs. 93.5), the IKDC score (93.3 vs. 93.1), knee instability and pivot-shift test. The SB group results were in accordance with the findings of the current study. They concluded that anatomical DB ACL restoration is not better than the SB technique. One advantage of the anatomic all-inside ACL restoration consists in the preservation of the gracilis tendon. Moreover, Crall et al. published a paper in which they describe an anatomic allinside ACL restoration technique using an autograft harvested from the quadriceps tendon. ${ }^{11}$ Its described advantages are a denser collagen matrix, a larger uniform graft, and less associated morbidities (numbness, pain with kneeling, anterior knee pain). An ACL tear is frequently associated with the rupture of the anterolateral ligament and anterolateral instability. Smith et al. described a minimally invasive technique, in which the reconstruction of the anterolateral ligament can be integrated easily and with minimum costs (equipment, expertise, operative time) in the anatomic all-inside ACL reconstruction procedure. ${ }^{12}$

This study also had few limitations. The inclusion of patients with associated lesions can be considered a limitation, but in the current circumstances, an isolated rupture of the ACL is rare. The study had no control group, and the follow-up time can be considered too short by some authors. Additionally, we did not use evaluation parameters such as the VAS score, therefore, subjective pain could not be assessed optimally. Also, the sample of patients might be too small to allow clear comparisons and development of recommendations.

\section{CONCLUSIONS}

Good to excellent preliminary outcomes of the anatomic all-inside ACL restoration seem to confirm the clinical and functional effectiveness of this technique based on a 6-month follow-up period. However, additional research with longer follow-up periods is required in order to prove the long term success of the procedure.

\section{CONFLICT OF INTEREST}

Nothing to declare.

\section{REFERENCES}

1. Fu FH, Bennett $\mathrm{CH}$, Ma CB, Menetrey J, Lattermann C. Current trends in anterior cruciate ligament reconstruction. Part II. Operative procedures and clinical correlations. Am J Sports Med. 2000;28:124-130.

2. Harner CD, Honkamp NJ, Ranawat AS. Anteromedial portal technique for creating the anterior cruciate ligament femoral tunnel. Arthroscopy. 2008:24:113-115

3. Mulcahey MK, David TS, Epstein DM, Alaia MJ, Montgomery KD. Transtibial versus anteromedial portal anterior cruciate ligament reconstruction using soft-tissue graft and expandable fixation. Arthroscopy. 2014;30:1461-1467.

4. Lubowitz JH, Ahmad CS, Anderson K. All-inside anterior cruciate ligament graft-link technique: Second-generation, no-incision anterior cruciate ligament reconstruction. Arthroscopy. 2011;27:717-727.

5. Kim SG, Kurosawa H, Sakuraba K, Ikeda H, Takazawa S, Takazawa Y. Development and application of an inside-to-out drill bit for anterior cruciate ligament reconstruction. Arthroscopy. 2005;21:1012.

6. Smith P, Schwartzberg RS, Lubowitz JH. No tunnel 2-socket technique: All-inside anterior cruciate ligament double-bundle retroconstruction. Arthroscopy. 2008;24:1184-1189.

7. Schurz M, Tiefenboeck TM, Winnisch M, et al. Clinical and Functional Outcome of All-Inside Anterior Cruciate Ligament Reconstruction at a Minimum of 2 Years' Follow-up. Arthroscopy. 2016;32:332-337.

8. Lubowitz JH, Schwartzberg R, Smith P. Randomized controlled tria comparing all-inside anterior cruciate ligament reconstruction technique with anterior cruciate ligament reconstruction with a full tibial tunnel. Arthroscopy. 2013;29:1195-1200.

9. Briggs KK, Lysholm J, Tegner Y, Rodkey WG, Kocher MS, Steadman JR. The reliability, validity, and responsiveness of the Lysholm score and Tegner activity scale for anterior cruciate ligament injuries of the knee: 25 years later. Am J Sports Med. 2009;37:890-897.

10. Hussein M, van Eck CF, Cretnik A, Dinevski D, Fu FH. Individualized anterior cruciate ligament surgery: a prospective study comparing anatomic single- and double-bundle reconstruction. Am J Sports Med. 2012;40:1781-1788.

11. 11.Crall ST, Gilmer BB. Anatomic All-Inside Anterior Cruciate Ligament Reconstruction Using Quadriceps Tendon Autograft. Arthrosc Tech. 2015;4:e841-e845.

12. Smith JO, Yasen SK, Lord B, Wilson AJ. Combined anterolateral ligament and anatomic anterior cruciate ligament reconstruction of the knee. Knee Surg Sports Traumatol Arthrosc. 2015 Nov;23(11):3151-6. 